\title{
STUDIJA TRANSFORMACIJE DELA INDUSTRIJSKE ZONE GRADA RAŠKE U „GRAD PO MERI PEŠAKA“
}

\section{STUDY TRANSFORMATION OF PART OF INDUSTRIAL ZONE OF RAŠKA TO "CITY BY MEASUREMENTS OF PEDESTRIAN"}

\author{
Strahinja Banović, Darko Reba, Fakultet tehničkih nauka, Novi Sad
}

\begin{abstract}
Oblast - ARHITEKTURA I URBANIZAM
Kratak sadržaj - Tema istraživanja kao i sam zadatak oveog rada zasniva se na naučno-istraživačkom radu, koji za cilj ima da pokakže kako „dobro“ urbano planiranje utiče na socijalizaciju stanovništva. Društvo i međuljudski odnosi su sve veći problem današnjice, jer ljudi jedni na druge gledaju samo kao na prepreke koje se nalaze na njihovom putu od tačke $A$ do tačke $B$, koje jednostavno samo treba zaobići. Dobrom arhitekturom, $i$ dobrim urbanim planiranjem i projektovanjem može se podstaći veća interakcija ljudi u prostoru, koji će ih privući u sebe svojim dešavanjima $i$ naterati da komuniciraju sa drugima, stvarajući novo okruženje, novi broj prijatelja, i na taj način će da bogate svoj društveni život i grade ga $u$ zajednici.
\end{abstract}

Ključne reči: Raška, urbanizam, urbana sociologija, sociologija naselja, socijalizacija,

Abstract - The topic of research as well as the task of this paper is based on scientific research work, which aims to suggest that "good" urban planning influences the socialization of the population. Society, and interpersonal relations are an increasing problem of today, because people look at each other only as obstacles that are on their way from point A to point B, which simply should be bypassed. Good architecture, good urban planning and discussion, can stimulate greater interaction of people in the space, which will attract them in their own affairs and make them communicate with others, creating a new environment, a new number of friends, and in this way will enrich their social life and build it in the community.

Key words: Raska, urban sociology, sociology of settlements, socialization

\section{UVOD}

Gledajući današnjicu iz ugla arhitekte, urbaniste, ili arhitekte urbaniste, u gradovima se kao struka susrećemo sa mnogim problemima vezanih za njihovo planiranje. Problem arhitektonskog projektovanja danas tj. jedan od njih jeste problem ,investiroskog projektovanja“ u kojem je struka nemoćna, čiji je krajnji ishod samo na štetu stanovništva, nacije i sveta.

\section{NAPOMENA:}

Ovaj rad proistekao je iz master rada, čiji mentor je bio prof. dr Darko Reba.
Takvim postupanjem se na žalost gubi jedan bitan segment dokaza istorije, jer je arhitektura jedan najbitniji svedok istorije, kreirajući sve više sterilnih objekata, bez ikakvog simbolizma, arhitektonskog poteza ili stila.

Duh mesta-(genius loci), što je istoimeni naziv za knjigu Kristijana Norberga Šulca i za koji se zalagao, često i pominjao jedan od naših najvećih imena arhitekture, profesor Mihajlo Mitrović i mnogi drugi, koji su se bavili ovom tematikom, kao da je negde zagubljen i apsolutno zanemaren jer je potpuno izgubljen u većini slučajeva.

Međutim, kada je u pitanju urbanizam i urbano planiranje, problem se ne svodi na samo jednu zgradu kao individuu, ili kao arhitektonski subjekat, već na čitav blok, naselje, grad ili državu u zavnisnosti od predmetnog plana koji se razmatra.

Kada govorimo o takvom planiranju jedne urbane celine, ili da je nazovemo ,zajednice objekata“ i javnih površina, ne možemo a da se ne dotaknemo teme po pitanju odnosa „svega sa svim“ u tim ambijentima.

Pod tim terminom mislimo na odnose objekata jedan prema drugom, saobraćaja i najbitnije odnos pešaka i samih korisnika tih površina, sa svim ostalim, takoreći njihov reciprocitet.

\section{CILJEVI ISTRAŽIVANJA}

Socijalizacija kao globalni problem danas, odnosno njen nedostatak, izaziva osećaj usamljenosti u punom gradu, i neprijatnost medju ljudima kao psihološko stanje većine. U mnogo slučajeva u svetu se dešava da zbog izostavljanja ljudskog faktora pri projektovanju, osobe koje žive $\mathrm{u}$ istoj zgradi se ne poznaju uopšte, ili možda znaju troje ili četvoro komšija oko sebe i na tome se sve završava, bez ikakve želje i mogućnosti za sticanje i razvoj poznanstva i prijateljstva.

Kreiranjem površina u kojima se konstantno dešava određena interakcija, koja uključuje ljude koji tu žive ili privlači turiste. Tako kreirana arhitektura će na taj način odavati totalno drugačiji utisak o tom mestu, dajući mu nov život i podstičući njegovu živost, jer ljudi su ti koji gradu daju atmosferu, a ne zgrade.

Cilj ovog izučavanja će biti pronalaženje rešenja za kreiranje, aktiviranje i podsticanje društvene socijalizacije izazvano kreiranjem ,dobre“ arhitekture i urbanizma u gradu.

$\mathrm{Na}$ delu industrijske zone grada Raške, pokušaćemo da kompletno planiranje podredimo čoveku i kreiramo za ljude, tj. u našem slučaju „PO MERI PEŠAKA“! 


\section{3.}

ISTRAŽIVANJE SOCIJALIZACIJE DANAS

Istorija istraživanja socioloških problema veoma je stara, jer još iz antičkog perioda postoje pisani tragovi koji obuhvataju sociološke probleme naselja. Takođe, jedan od najvećih doprinosa u urbanoj socijalizaciji donela nam je „,̌ikaška škola“ sa svojim dugogodišnjim istraživanjima na ovom polju. Odnos ljudi je u mnogome zavisan od samog urbanog planiranja i kreiranja mesta za socijalizaciju, koje će izazvati interakciju. Iz tih razloga je potrebno izučavanje o međuzavisnosti institucija ljudskih grupa u sociološkom prostoru. U sociologiji se posebno izučava uticaj prirodne okoline na čoveka, kao i uticaj čoveka na prirodu, jer se čovek mora staviti u centar svega.

Grad je po definiciji Maksa Vebera (Maks Veber „Privreda i društvo“) ,naseljeno mesto, u kojima su misleći se na naselje, kuće tesno zbijene i povezane u tako obimnu naseobinu da se stanovništvo međusobno ne poznaje“, što je specifično za ovakvu organizacionu grupu ljudi. On uvek predstavlja mesto rađanja i izvor ljudske slobode $\mathrm{i}$ to je nešto neosporivo, jer podstiče prihvatanje raznolikosti i ljudsku individualnost. Grad i individua su snage koje se oslanjaju jedna na drugu, iz čega proističu i javna moć i individualizam. Definitivno je da grad isijava način života civilizacije, ali takođe isijava siromaštvo i otuđenost.

Gradovi obuhvataju šarolikost ljudi i kultura veoma različitih načina života između kojih postoji samo neznatna komunikacija, najveća ravnodušnost i najveća tolerancija, povremeno žestoka borba i najoštriji konflikt. Pri projektovanju grada, kada se bavimo urbanom sociologijom, trebalo bi razmišljati u pravcu kako kreirati grad po meri ljudi? Kada kažemo ,grad po meri pešaka“, mislimo da se time upustimo $u$ probleme dijaloga korisnika sa samim dešavanjima u mestu i okolini. Problem odnosa korisnika sa rekom (ako je ima, što je slučaj u ovom radu), je takođe veoma bitan faktor koji će uticati na razvijanje plana, jer je sama obala reke urbana površina koju treba iskoristiti maksimalno.

To je ambijent koji bi trebalo da služi za odmor, zabavu, razonodu, šetnju, druženje itd. Kada dođemo do bavljenja ovim problemom, moramo proučiti odnos reke i grada, kako grad odvući na reku i približiti ga vodi, jer je ona nešto najdragocenije što grad može posedovati.

\section{LOKACIJA}

Opština Raška ima meridijanski pravac pružanja dolinom Ibra. Na severu putnom i železničkom vezom povezana je sa Zapadnomoravskom dolinom i Šumadijom, a na jugu sa Kosovom i Metohijom. Dolinom Jošanice, na istoku, povezana je sa Aleksandrovačkom Župom i Toplicom, a na jugozapadu, dolinom reke Raške, sa Crnom Gorom i novopazarskim delom Raške oblasti. Lokacija se nalazi u industrijskoj zoni naselja Raška, okrenuta širom stranom prema magistralnom putu koji povezuje Novi Pazar, Kosovsku Mitrovicu i Beograd sa jedne strane i prema reci Ibar sa suprotne strane, celom dužinom. Predmetna lokacija sadrži 102 parcele K.O.Raška, čija ukupna površina zauzima $131275 \mathrm{~m} 2$, odnosno 13.1ha. (uzeto sa http://www.geosrbija.rs), koje će biti ujedinjene u jedinstvenu parcelu te površine (zamišljamo idealan slučaj studije). Oblik građevinske parcele je nepravilan, sa ravnim terenom. Objekti u neposrednom okruženju su spratnosti od $\mathrm{P}+1$ do $\mathrm{P}+6+\mathrm{Pk}$, građeni $\mathrm{u}$ različitim periodima $\mathrm{XX}$ veka, sa karakterističnim modernističkim kao $\mathrm{i}$ industrijskim stilom.

Prema nameni su stambeni, poslovni, industrijski locirani na granici sopstvenih parcela prema bočnim susedima kao i prema ulici. Planirana lokacija nalazi se u blizini glavnog mosta koji spaja Vlasovo i grad Rašku i u direktnom je kontaktu sa istim. Na udaljenosti je 300m od centra grada, tj. glavnog trga.

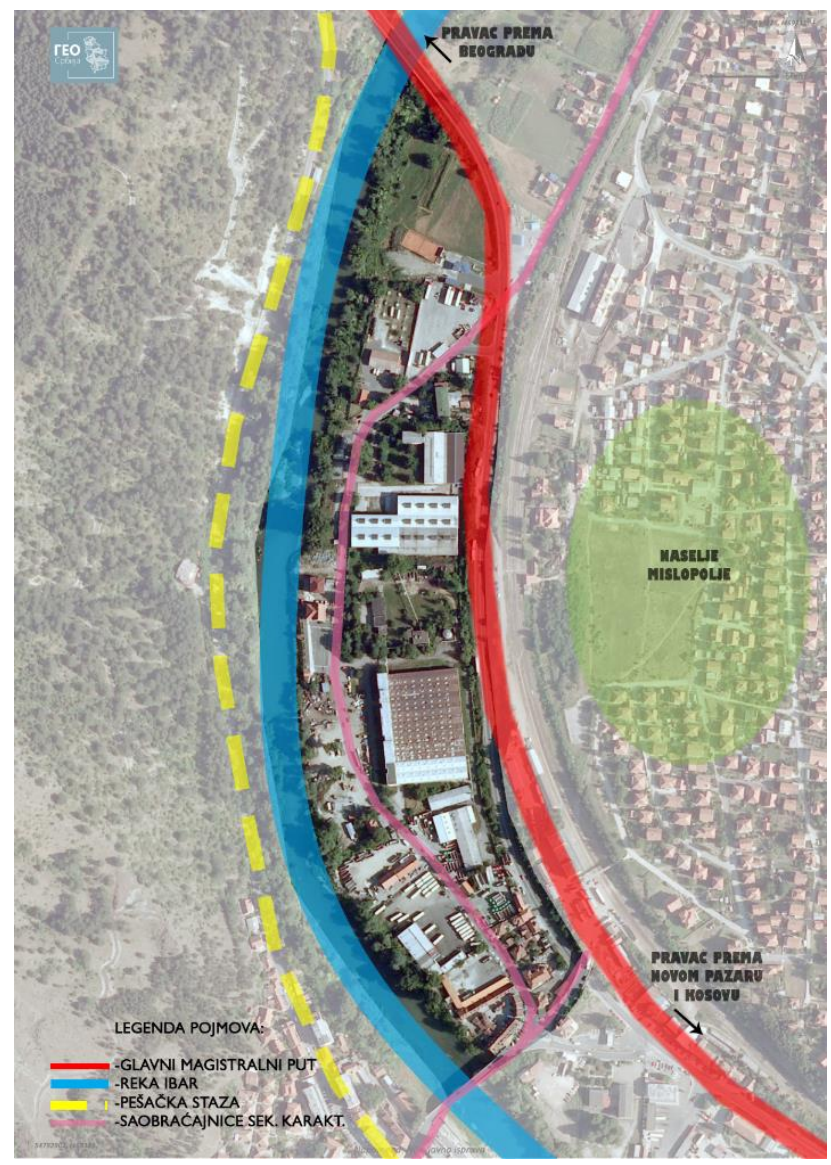

Slika 1. Odabrana lokacija ${ }^{l}$

\section{IDEJNI KONCEPT}

Koncept projekta obuhvata arhitektonsko urbanistički potez, koji će uticajem novokreiranog prostora aktivirati socijalizaciju, eduakciju i rekreaciju u ovom gradu. $\mathrm{Na}$ takav način će pokazati da se pešacima treba dati površina zemlje, a da se automobilski saobraćaj odvija ispod. Primenom principa održive arhitekture implementiranjem zelenila (stabla jorgovana), a i preko sistema za sakupljanje kišnice koja se može koristiti za sanitarnu vodu, štitimo pijaću vodu koja važi za jednu od najčistijih u Srbiji. Ako se pitate zašto baš jorgovan, takav potez nije ništa novo u ovom delu Srbije.

Naime, srpski kralj Uroš I Nemanjić je želeo da na poseban način dočeka svoju buduću suprugu, pa je naredio da se pre njenog dolaska duž nepristupačne doline Ibra posadi prelepo cvetno drveće jorgovana kako bi je predeo podsećao na njenu rodnu Provansu. Sure litice

1 www.geosrbija.rs 
doline Ibra sakrili su veliki grozdasti cvetovi ljubičaste boje, a taj stenovit kraj postao je prilično pitom.

Kompletna lokacija prepuna drveća jorgovana nije takva bez razloga. Znajući cvet jorgovana možete samo da zamislite lepotu prizora u cvetanju i opojni mirisi koji će definitivno očarati svakog ko prođe tuda magistralnim putem ili posetiocima ovog mesta što će definitivno postati NOVI SIMBOL RAŠKE, ali simbol sa razlogom!

\section{PROSTORNI KONCEPT}

Pored ankete koju smo koristili kao ulazne reference $\mathrm{u}$ procesu projektovanja uzimajući u obzir mišljenje korisnika kao najbitnijih aktera, kroz analize kao drugi deo ulaznih referenci pozabavili smo se kako da povežemo predmetnu lokaciju, sa gradom. To smo uradili kroz tri vrste povezivanja:

1.-Povezivanje događaja u gradu sa pešacima

2.-Povezivanje pešaka sa rekom Ibar, kao draguljem grada

3.-Povezivanje grada i lokacije sa rekom kao zapostavljenim elementom.

Ove vrste povezivanja su nam dale niz prostornih programa koje smo primenili u traženju koncepta.

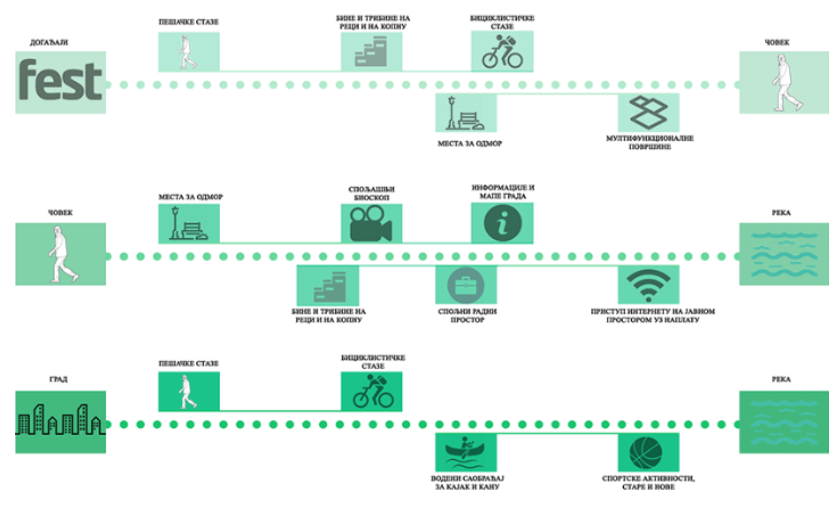

\section{Slika 2. Dijagram povezanosti ${ }^{2}$}

Kao logičan sled istraživanja, morali smo doći do razmatranja programskih aktivnosti koje bi nam pomogle $\mathrm{u}$ aktiviranju socijalizacije tokom cele godine. Na takav način bismo uvek imali aktivnosti koje će oživljavati grad u kontinuitetu tokom cele godine, nezavisno od starosnih generacija.

Još jedan način podsticanja socijalizacije jeste aktiviranjem prizemlja raznim sadržajima kao jedan od glavnih potencijala projekta za povećanje društvene interakcije. Za cilj ima da korisnike uvlači u svoj prostor iz tačke A do tačke B, zadržavajući ih što duže u sebi zbog interesantnosti svoje raznolikosti.

\subsection{Funkcionalni raspored lokacije}

Funkcionalna podela lokacije deli se u tri osnovne grupe: zonu edukacije, rekreacije i stanovanja. Sve tri zone su povezane stazama za pešake i bicikliste, dok se u automobilskom saobraćaju „prekida“ saobraćaj na

\footnotetext{
${ }^{2}$ Autorski rad - Strahinja Banović
}

površini zemlje na ulazima u ovaj deo, koji je rešen podzemnim tunelom, koji je zaštićen drenažnim cevima do podzemnih voda koje postoje od reke Ibar kao i svi ostali objekti u neposrednoj blizini.

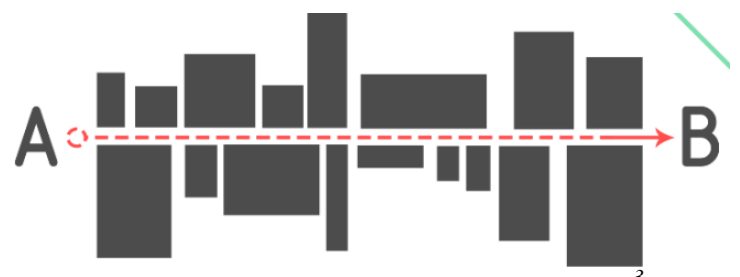

Slika 3. Dijagram aktivacije prizemlja ${ }^{3}$

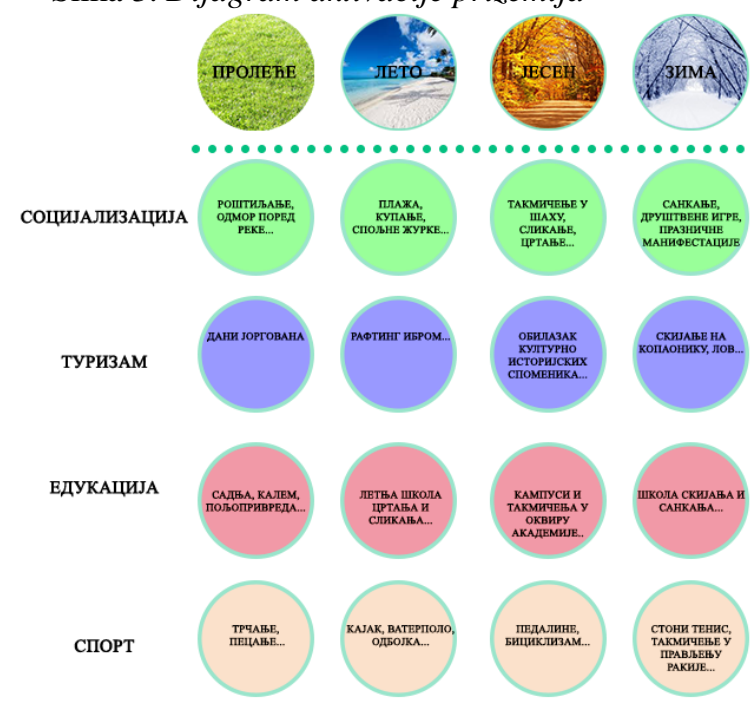

Slika 4. Programski predlog sadržaja

U zoni stanovanja su primenjeni objekti kolektivnog stanovanja jednaki po tipologiji ali svaki različit $\mathrm{i}$ specifičan na svoj način, tako da predstavljaju jednu zanimljivu stambenu celinu, koja će biti prepoznatljiva po svom jedinstvu u različitosti.

Objekti će imati ulogu da podstiču interakciju između komšija orijektisani tako da u budućnosti zajednički prostori stanara jedne zgrade razbiju barijeru i sastave taj prostor sa stanarima druge zgrade i na taj način prošire svoje zajednične prostore, i započnu interakciju preko tih objekata sa svima oko sebe. Svaki objekat ima sopstvenu garažu za parking automobila ispod površine zemlje kako bi automobili izgubili svako pravo da budu na površini zemlje i zagađuju okolinu.

Tu je plasiran i market na 3 etaže kako bi se stanovnicima ovog dela grada obezbedio pristupačan prostor za trgovinu i potrepštine svih vrsta, kao i za prezentaciju i prodaju novih domaćih proizvoda o čemu će se više govoriti u konceptualnom delu opisa.

Što se tiče zone za edukaciju ona sadrži studentski kampus „Dolina Jorgovana“, koji u sebi ima sve potrebne sadržaje koji karakterišu jedan takav vid kampusa „ogrnut“ drvećem jorgovana. Kreiran je centralni trg sa prostorima za sedenje, okupljanje i druženje, kao i lokalima, „Concept Store-ovima“ različitog sadržaja i raznolikih igleda kao vid ,aktivacije prizemlja“ u cilju poboljšanja interakcije. U dodatne sadržaje tu još spadaju veliki spoljni bioskopi i pozorište kao multifunkcionalni

\footnotetext{
3 Autorski rad - Strahinja Banović

${ }^{4}$ Autorski rad - Strahinja Banović
} 
prostor koji može leti da služi kao jedno od ta dva ili oba istovremeno. Kao najbitniji objekat tu se nalazi Umetnička akademija kao jedan definitivno potreban objekat ovom gradu prepunom umetnosti na svakom koraku. Leti takođe studenti mogu da pripremaju priredbe i izvedbe kao i mini koncerte i razne manifestacije na temu umetnosti, scenskog dizajna, muzike itd., dok se zimi tribine sklope $\mathrm{i}$ to se pretvori $\mathrm{u}$ klizalište gde se aktivira škola umetničkog klizanja.

U delu rekreacije nalazi se mnoštvo sportskih sadržaja koje ćete videti u grafičkim prilozima da ih ne bismo nabrajali bespotrebno. Kreiranni su tereni za fubal, tenis, otvoreni bazeni itd., za letnje sportove, kao i adrenalin parkovi. Zimi se organizuju škola klizanja, šaha itd...

Ono što je bitno jeste to da je planirana jedna velika možemo reći sportska škola, za sve vrste sportova koje postoje na parceli, što će povećati i broj turista za razna takmičenja, a naravno i podstaći razvijanje zdravog života. Škola obuhvata: fudbal, odbojku, tenis, košarku, kajak i kanu, šah, badmington, plivanje, fitnes i bodibilding, adrenalinske sportove, od kojih će određene škole biti sezonske, a određene tokom cele godine.

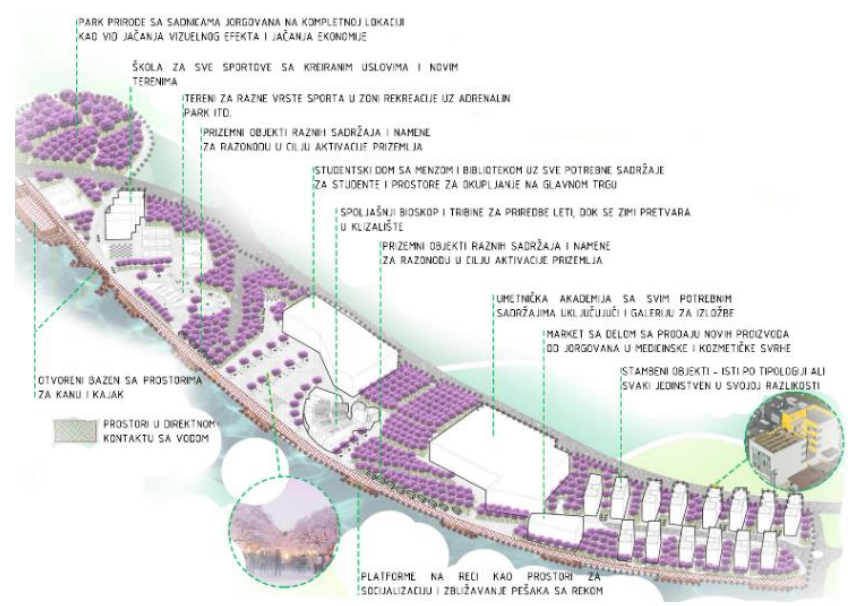

Slika 5. Dijagram koncepta ${ }^{5}$

\section{ZAKLJUČAK}

Kao usmerivači pravca ka većoj socijalizaciji u kojem smo išli držeći se pravila struke i određenih informacija prikupljenih kroz istraživanje došli smo do rešenja. Rešenje kao ideja je ispunilo svoju misiju da na neki način probudi svest građana, kao najbitnije aktere u gradu, o potrebnim prostorima za socijalnu interakciju, što može da proizvede u budućnosti lavinu akcija pri kreiranju ovih mesta ili bar delić ovoga.

Kvalitet samog rešenja se može izmeriti na osnovu ankete u završnoj fazi koja je merilo kvaliteta rešenja, odnosno najveći kvalitet je veliko zadovoljstvo korisnika u odnosu na predstavljeno rešenje. Rad je pokrio više oblasti, kao što su rekreacija, stanovanje i edukacija, sve to spojeno jednom niti kojoj smo težili a to je SOCIJALIZACIJA.

Reč koja je pokrenula celo ovo istraživanje. Ono što bih izdvojio kao savet studenta, studentima, jeste to da se uključe u bavljenje ovom tematikom, bilo kroz gradove, naselja ili „urbanu akupunkturu“, bitno je da ova tema mora da zaživi. Čovek bez čoveka može ali to ne znači da treba tako, mi smo zajednica, i treba je tako i doživeti i graditi je bilo gde. Ovaj rad je samo delić velike slagalice pojma socijalizacije, koji je obuhvatajući samo opšte stavove korisnika, pokrenuo lavinu pitanja na koje se mora naći odgovor, kako bi smo se ponovo zbližili sa ljudima i vratili se prirodi.

Kada kažemo „vratiti se prirodi“ misli se na provođenje vremena više u javnim prostorima a manje u objektima, jer se tako jedino možemo zbližiti sa ljudima. Čist primer su studentski domovi, jer zamislite totalnog neznanca koji sa vama provodi vreme svakog dana minimum 15 sati i koji vam postane kao neko najrođeniji, jer sa njim delite prostor, život, muku, sreću... Stoga, kada bismo isti ovaj šablon svakodnevno primenjivali na javne prostore, zamislite tu porodicu koju krojite.

Desetine ljudi postane vam deo porodice koje nemaju nikakve krvne veze sa vama, ali je prostor taj koji vas spaja i postaje deo vas kao i ljudi u njemu. Nadam se iskreno da će ovaj rad doprineti podsticanju bavljenja ovom temom jer smo mi ti koji menjamo svet, a ne on nas, jer mi smo njegovi kreatori i kako ga kreiramo takav će nam biti i izazivaće u nama ono što smo uradili. Zato je moje mišljenje da se treba baviti ovom tematikom što više i kreirati takve prostore jer je društvena zajednička aktivnost i interakcija oličenje zdrave sredine i zdravog ŽIVOG grada!

\section{LITERATURA I KORISNI ČLANCI}

[1]. Jan Gehl - Gradovi za ljude

[2]. Rudi Supek - Grad po mjeri čovjeka

[3]. Darko Reba, Marina Carević Tomić -

Urbanistička studija povezivanja Novog Bečeja i reke

Tise (prezentacija studentskih radova)

[4]. Darko Reba- Ulični sistemi i urbana morfologija

[5]. Darko Reba, INTERNA PREDAVANjA

[6]. Marta Minić (Master rad) - Regeneracija

braunfild lokacija: Ka jačanju socijalne kohezije, (uvodni deo)

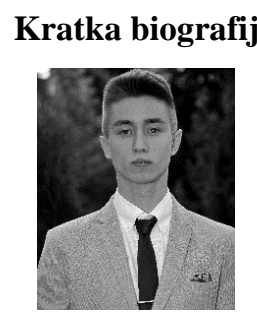

Strahinja Banović, rođen je u Novom Pazaru 1995. god. Osnovne akademske studije završio je 2018. god na Fakultetu tehničkih nauka, studijski program Arhitektura na Državnom univerzitetu u Novom Pazaru. Student master studija FTN Novi Sad, smer „Arhitektonsko i urbanističko projektovanje".Diplomirao 2019. kod mentora prof. dr Darka Rebe.

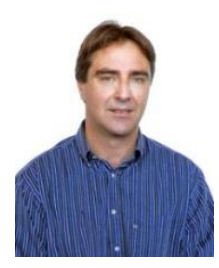

Dr Darko Reba, Redovni profesor na Fakultetu Tehničkih Nauka u Novom Sadu.

\footnotetext{
${ }^{5}$ Autorski rad - Strahinja Banović
} 